\title{
PROPUESTA METOdOLÓGICA PARA EL ANÁLISIS DE LOS CÓDIGOS DECORATIVOS: COMPARANDO PIEDRAS Y CERÁMICA
}

\author{
M. Pilar Prieto M. ${ }^{1}$ y Manuel Santos E. ${ }^{2}$
}

\section{* INTROdUCCIÓN}

Resumen

Hay principios estructurales que modelan las formaciones socioculturales, así como la cultura material concretiza la espacialidad de estas formaciones. Si, además, hay compatibilidad estructural entre códigos, la organización espacial de los diseños expresará los patrones

de regularidad formal. Para caracterizar estos patrones y acceder a la concepción del espacio de algunas formaciones culturales, comparamos

dos ámbitos fenomenológicos de larga duración, cerámica y arte rupestre de Galicia (NO de España) y del valle del Aconcagua (Chile Central). Aunque cada cultura tiene su propia idiosincrasia material, cada patrón de racionalidad es representado por una estructura que se puede encontrar en formaciones socioculturales análogas. Nuestra intención es encontrar dicha estructura y comprobar la validez universal de la compatibilidad de códigos.

Palabras claves: análisis estructural - cerámica - arte rupestre sociedades preestatales - sociedades protoestatales - España - Chile. Abstract
If structural principles model socio-cultural formations, material
culture concretizes their spatiality. If there is also a structural
compatibility between the codes involved, then the spatial
organization of the designs should also express patterns of formal
regularity. This paper compares two long-lasting phenomenological
ambits - pottery and rock art- from Galicia (NW Spain) and the
Valley of Aconcagua (Chile) in order to characterise shared patterns
of spatial regularity and access the underlying notions of space.
Although each culture has its own material idiosyncracy, each pattern
of rationality is represented by a structure that may be found in
similar socio-cultural formations. Our aim is to discover this formal
structure, and gauge the universal validity of code compatibility.

Key words: structural analysis - pottery - rock art - pre-state societies - proto-state societies - Spain - Chile.

Recibido: marzo 2007. Aceptado: enero 2009.
Pretendemos llevar a cabo un análisis estructural de la cultura material de dos momentos de la prehistoria en Europa. Concretamente trataremos de abordar la deconstrucción de los principios que estructuran la decoración de la cerámica y el arte rupestre en sociedades de la prehistoria reciente y protohistoria. En el caso europeo, incluimos en la prehistoria reciente aquellas sociedades que han dejado de ser primitivas pero aún no han alcanzado la complejidad social de un Estado, mientras que las sociedades protohistóricas se caracterizan por una mayor división del cuerpo social que se traduce, entre otras cosas, en la existencia de instituciones de poder organizadas sistemáticamente. ${ }^{3}$

Nuestro objetivo es caracterizar los patrones de regularidad espacial para poder acceder a la concepción del espacio de cada tipo de formación sociocultural, es decir, definir espacios decorativos a lo largo del tiempo comparando elementos procedentes de contextos diferentes para poder comprobar si los cambios espaciales que se producen en los patrones de los diseños están relacionados con cambios en las sociedades que los producen, siendo conscientes de los procesos históricos particulares de cada zona o continente. Los antecedentes de nuestro trabajo se

\footnotetext{
${ }^{1}$ Laboratorio de Patrimonio, Paleoambiente e Paisaxe (IIT, Universidad de Santiago de Compostela), Grupo de Investigación Sincrisis. RU Monte da Condesa s/n. Campus Universitario Sur. 15782 Santiago de Compostela, ESPAÑA. Email: pilar.prieto@usc.es

2 Laboratorio de Arqueoloxía da Paisaxe. Instituto de Estudos Galegos Padre Sarmiento (CSIC-Xunta de Galicia). San Roque, 2.15704 Santiago de Compostela, ESPAÑA. Email: manuel.santos.estevez@usc.es

3 Aunque las sociedades protohistóricas europeas no responden a una organización estrictamente estatal, sino más bien protoestatal, y hasta la invasión romana no se puede hablar de Estado propiamente dicho, éstas se aproximan más a un patrón de racionalidad estatal, y así las abordaremos para desarrollar este estudio.
} 
encuentran en algunas publicaciones de los últimos años (Cobas et al. 1998; Cobas y Prieto 1998; Prieto 1999a, 2007; Prieto et al. 2003).

Utilizaremos dos elementos de cultura material muy diferentes como marco empírico para la comparación, bien contextualizados actualmente en Europa. Para completar nuestro análisis y comprobar si estos modelos funcionan en un ámbito más global, abordaremos de forma preliminar los mismos elementos de cultura material en una zona concreta de Sudamérica (Figura 1).

Siguiendo la línea de nuestros trabajos anteriores (Prieto 1999a, 1999b; Santos y Criado 2000; Prieto et al.2003; Santos 2008a, 2008b), partimos de la base que los productos sociales que se crean en el seno de una comunidad se encuentran íntimamente relacionados con todos los ámbitos de su realidad, tanto material como imaginaria, y por ello las características y elementos de una determinada sociedad se reflejan en todos los ámbitos de su producción material. Esto da lugar a relaciones de complementariedad entre códigos, tal como propugna Lévi-Strauss (1987) para el estudio de los mitos o manifestaciones de distintos ámbitos de cultura material, permitiendo que desde cualquiera de los códigos producidos por una misma cultura se puedan estudiar los demás, puesto que responden a las mismas pautas culturales (Lévi-Strauss 1986; Criado 1993).
Este enfoque entiende que la espacialidad es una herramienta de la sociedad, por lo tanto, estudiar las materialidades de la decoración en diferentes soportes a lo largo de un tiempo prolongado, permitirá definir mejor el concepto de espacio de dichas sociedades. El análisis de los espacios decorativos es un método que sirve para estudiar las formaciones socioculturales. Creemos que la decoración se materializa a través de formas espaciales cuya organización estará determinada por los códigos de representación del espacio vigentes dentro de una determinada formación sociocultural. Por lo tanto, nuestras hipótesis serán las siguientes: 1) Existe compatibilidad estructural en los espacios decorativos de los diferentes elementos de cultura material de una misma sociedad; 2) Existe coherencia estructural en dichos espacios cuando se detecta un cambio social. De hecho, no sólo la propia iconografía (figurativa o abstracta) nos habla del tipo de sociedad, sino la manera de organizarla y concebirla espacialmente en el soporte; 3) El cambio formal en la organización del espacio de las representaciones puede estar reflejando un cambio cultural en el patrón de racionalidad de las sociedades.

Para interpretar la espacialidad es muy útil usar, como punto de referencia, el modelo sociológico de La antropología política de Clastres (1981), quien caracteriza las líneas de fuerza de dos formaciones sociales y dos patrones de racionalidad totalmente opuestos, las sociedades primitivas y las sociedades estatales.

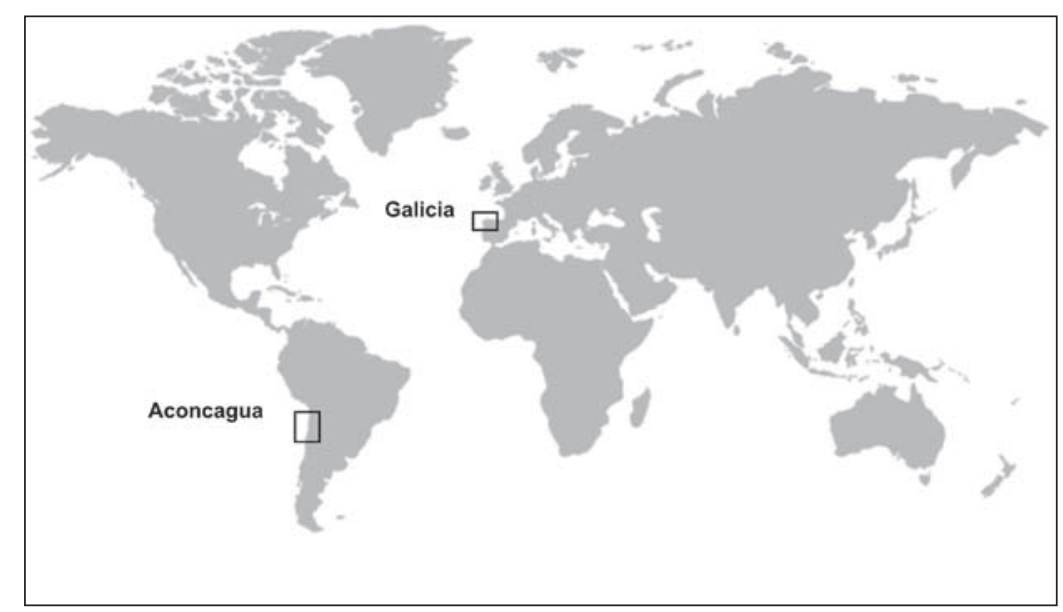

Figura 1. Localización de las zonas estudiadas, Galicia y Chile. 
Las primeras se definen por la homogeneidad interna del cuerpo social y por la diversidad externa entre comunidades (supralocal), mientras que las segundas, son el extremo opuesto, ya que presentan una fuerte división-separación-diversidad interna del cuerpo social, mientras que en un nivel supralocal-externo presentan homogeneidad. Las sociedades que incorporamos en este estudio se localizan justo a partir del momento en el que la división y complejidad sociales son inevitables, pero todavía no han desarrollado la complejidad de las sociedades estatales.

En coherencia con lo anterior, para desarrollar el análisis entendemos el soporte de la decoración como panel que expresa espacialidad social. Consideraremos los siguientes aspectos: temática, morfología y 'lectura' de la decoración. Aplicamos una metodología ya publicada (Prieto et al. 2003), haciendo una comparación más directa de los distintos elementos que componen la cerámica y el arte rupestre:

- La temática implica tres aspectos de la decoración: elementos, motivos y esquemas decorativos.

- La morfología implica cinco aspectos de la decoración: ubicación, composición, delimitación, orientación y visibilidad.

- La lectura 'sin entender' implica tres aspectos de la decoración: sentido de la lectura, variedad de puntos de vista, sentido del movimiento.

Si bien trataremos únicamente aquellos aspectos más significativos en ambos tipos de paneles y que nos permiten realizar la comparación, no viene al caso comparar técnicas decorativas o aspectos muy específicos del soporte entre dos formas de cultura material tan distintas.

Analizaremos comparativamente arte rupestre y cerámica, ya que se advierten claros paralelismos entre estos elementos de la cultura material, que parecen transformarse paralela y sincrónicamente con los cambios producidos en las respectivas sociedades y culturas en las que se hallan inscritos. Además, si es cierto que existe una compatibilidad de códigos entre cultura material, sociedad y cultura, deberíamos advertir procesos y estructuraciones similares en la cultura material de otras culturas del mundo. Para asegurar que dichos paralelismos no son debidos a contactos o difusiones, nos hemos ido al centro de Chile (y complementariamente al sur del Norte Chico), donde encontramos estilos de arte rupestre y cerámicos que guardan, en el nivel estructural, similitudes significativas con los petroglifos y con la cerámica de la Europa atlántica.

Partimos de Europa porque es un registro bien conocido por nosotros (hablamos principalmente de la Europa atlántica para poder validar de manera sistemática nuestra metodología, sin embargo podría aplicarse a otras zonas de Europa, desde Iberia hasta Escandinavia), y seleccionamos la cuenca superior del río Aconcagua en Chile, por tratarse de un registro familiar. ${ }^{4}$ Aunque somos conscientes de que estas sociedades presentan una mayor complejidad que la que aquí ofrecemos, hemos visto necesario organizar esta distribución cronológica en dos grandes fases para poder establecer con coherencia comparaciones con esta zona sudamericana.

\section{- Europa como ejemplo: Noroeste DE EsPaña}

El panorama arqueológico está estudiado de manera muy local y regional en Europa, y aunque el cuadro que ofrecemos seguidamente con la información básica sobre la cronología e hitos socioculturales más significativos y el tipo de cultura material más destacada se centra especialmente en el noroeste de España, en cierto grado sería extensible al resto de Europa Occidental, ya que en esta zona los cambios sociales y materiales se han desarrollado con cierta simultaneidad en las distintas regiones. La Tabla 1 muestra de forma muy esquemática los desarrollos sociales y en cultura material.

\footnotetext{
${ }^{4}$ Gracias a nuestra participación en el proyecto FONDECYT 1040153:
"Forma, contenido, sustancia y expresión en el arte rupestre de la

${ }^{4}$ Gracias a nuestra participación en el proyecto FONDECYT 1040153:
"Forma, contenido, sustancia y expresión en el arte rupestre de la cuenca superior del río Aconcagua”, cuyo investigador responsable es Andrés Troncoso.
} 


\begin{tabular}{|c|c|c|c|c|c|c|}
\hline Sociedad & $\begin{array}{l}\text { Cronología } \\
\text { cal.AC-DC }\end{array}$ & $\begin{array}{l}\text { Adscripción } \\
\text { cultural }\end{array}$ & $\begin{array}{c}\text { Formaciones } \\
\text { socioculturales }\end{array}$ & $\begin{array}{l}\text { Aspectos a } \\
\text { destacar }\end{array}$ & Cerámica & Arte rupestre \\
\hline \multirow[t]{5}{*}{ Preestatal } & & $\begin{array}{l}\text { Neolítico } \\
\text { Inicial }\end{array}$ & $\begin{array}{l}\text { Soc. primitiva } \\
\text { Bandas cazadores }\end{array}$ & $\begin{array}{l}\text { Ultimos } \\
\text { cazadores }\end{array}$ & \multirow[b]{2}{*}{$\begin{array}{l}\text { C. Incisas } y / 0 \\
\text { Impresas }\end{array}$} & $\begin{array}{l}\text { Arte Levantino } \\
\text { (Mediterráneo) }\end{array}$ \\
\hline & $4500-2900$ & $\begin{array}{l}\text { Neolítico } \\
\text { Medio }\end{array}$ & \multirow{2}{*}{$\begin{array}{l}\text { Disolución SP } \\
\text { Soc. segmentarias } \\
\text { Grupos domésticos } \\
\text { agricultores }\end{array}$} & $\begin{array}{l}\text { Constructores } \\
\text { de monumentos }\end{array}$ & & \\
\hline & $3000-2400$ & $\begin{array}{l}\text { Neolítico } \\
\text { Final }\end{array}$ & & $\begin{array}{l}\text { Grandes aldeas } \\
\text { campesinas }\end{array}$ & $\begin{array}{l}\text { Cerámicas Inciso- } \\
\text { metopadas }\end{array}$ & Estilo Atlántico \\
\hline & $2600-1400$ & $\begin{array}{l}\text { E. Bronce } \\
\text { Inicial }\end{array}$ & \multirow{2}{*}{$\begin{array}{l}\text { Soc. protoheroicas } \\
\text { Guerreros } \\
\text { Campesinos } \\
\text { primitivos }\end{array}$} & $\begin{array}{l}\text { La fragmen- } \\
\text { tación del } \\
\text { territorio }\end{array}$ & C. Campaniforme & \multirow{2}{*}{$\begin{array}{l}\text { Estilo Atlántico } \\
\text { Estilo Atlántico }\end{array}$} \\
\hline & $1500-800$ & $\begin{array}{l}\text { E. Bronce } \\
\text { Final }\end{array}$ & & $\begin{array}{l}\text { Las comunida- } \\
\text { des en conflicto }\end{array}$ & $\begin{array}{l}\text { C. Incisas } y / 0 \\
\text { Impresas }\end{array}$ & \\
\hline \multirow[t]{2}{*}{ Protoestatal } & $900-500$ & E. Hierro I & \multirow[t]{2}{*}{$\begin{array}{l}\text { Soc. protoestatales } \\
\text { Soc. heroicas }\end{array}$} & \multirow[t]{2}{*}{$\begin{array}{l}\text { La formación } \\
\text { de la sociedad } \\
\text { heroica }\end{array}$} & C. Incisas & Estilo Atlántico \\
\hline & $400-139$ & E. Hierro II & & & $\begin{array}{l}\text { C. Incisas y/o } \\
\text { Impresas, Bruñidas } \\
\text { y Estampilladas }\end{array}$ & $\begin{array}{l}\text { Estilo } \\
\text { Esquemático } \\
\text { Atlántico }\end{array}$ \\
\hline Estatal & $139-409 \mathrm{DC}$ & E. Hierro III & Estados Aristocracia & $\begin{array}{l}\text { Romanos: La } \\
\text { creación de } \\
\text { Gallaecia }\end{array}$ & $\begin{array}{l}\text { C. Incisas y/o } \\
\text { Impresas, Bruñidas } \\
\text { y Estampilladas }\end{array}$ & $\begin{array}{l}\text { Estilo } \\
\text { Esquemático } \\
\text { Atlántico }\end{array}$ \\
\hline
\end{tabular}

Tabla 1. Cuadro cronocultural del noroeste de España.

Describiremos someramente las características que definen, por un lado, las sociedades y cultura material de la prehistoria reciente (sociedades preestatales) y, por otro, las de la Segunda Edad del Hierro (sociedades protoestatales), momento en el que se producen cambios significativos de cara a la complejización de la sociedad en Europa.

\section{Sociedades preestatales}

En términos generales, la cronología del estilo Atlántico de arte rupestre se inicia hacia 3000 AC y finaliza en torno a $500 \mathrm{AC}$ (Santos 2005). Este marco cronológico coincide con el desarrollo del Neolítco Final, Edad del Bronce y Primera Edad del Hierro, que a grandes rasgos se corresponde con un tipo de organización social que, según qué escuelas, han sido clasificadas como jefaturas, sociedades guerreras, heroicas, etc. En todo caso se trata de sociedades preestatales, semiitinerantes, pero con un desarrollo de la complejidad social que definitivamente ha abandonado la igualdad, siendo detectables evidentes signos de jerarquización, aunque dicha desigualdad parece expresarse especialmente en el ámbito simbólico (Kristiansen 2001; Kristiansen y Larsson 2006). Esta circunstancia se reflejaría en la ausencia de grandes sistemas de almacenaje, escasa complejidad en la construcción arquitectónica y abundancia de objetos de adorno personal de lujo, especialmente armas metálicas y ornamentos de oro. Estas son el tipo de comunidades que realizaron el arte rupestre atlántico y la cerámica contemporánea en la cual destaca la denominada cerámica Campaniforme en la prehistoria reciente en Europa.

Estilo Atlántico (EA). En las tres grandes áreas con arte rupestre de la prehistoria reciente: Alpina (Mont Bego y Valcamonica), Escandinava y Atlántica (Noroeste de Iberia e Islas Británicas), el paisaje construido se caracteriza por su vinculación a vías de tránsito, por su asociación al desplazamiento por el territorio, describen un paisaje que se comprende con el movimiento a través de él, y se corresponde con comunidades semiitinerantes (Bradley 1997; Santos y Criado 1998, 2000). En el área Atlántica hemos definido el estilo de arte rupestre denominado Atlántico, compuesto fundamentalmente por dos tipos de diseños: 
1) Geométricos, como cazoletas, círculos simples, círculos concéntricos y laberintos, y 2) Figurativos: cérvidos, caballos, serpientes, antropomorfos, podomorfos y armas. Estilísticamente esta serie de petroglifos se define por las características formales presentadas en la Tabla 2 (Santos 2004).

Cerámica Penhay Campaniforme. Aunque los elementos decorativos utilizados son siempre geométricos de tendencia rectilínea (línea, zigzag, reticulado, con gran riqueza en sus variantes), se detectan al menos tres rupturas estilísticas hasta llegar al momento en el que se desarrolla la cerámica Campaniforme (que es contemporánea a buena parte del EA), que básicamente consiste en un aumento de la complejidad espacial de los diseños: 1) Se inicia con una unicidad en el diseño en los momentos más antiguos (que aquí no mostraremos dado su alejamiento cronocultural con el arte rupestre); 2) Se pasa por una compartimentación espacial vertical realizada con motivos de gran tamaño, siendo necesario observar la decoración de los recipientes en sentido circular-horizontal (esta cerámica es denominada Inciso-metopada o Penha); 3) Hasta llegar al comienzo de la horizontalidad de los diseños con la cerámica Campaniforme, en los que la lectura obligada del panel se hace en sentido oblicuo-vertical, destacando la fuerte horizontalidad de los elementos decorativos, independientemente de sus características y orientaciones individuales. Las características de la decoración de esta cerámica,

\begin{tabular}{|c|c|c|c|}
\hline $\begin{array}{l}\text { Aspectos formales a } \\
\text { considerar en el panel }\end{array}$ & Estilo Atlántico & Cerámica Penha & $\begin{array}{c}\text { Cerámica } \\
\text { Campaniforme }\end{array}$ \\
\hline Elementos decorativos & $\begin{array}{l}\text { Punto, línea y círculo. Se disponen en } \\
\text { torno a un punto central. }\end{array}$ & \multicolumn{2}{|l|}{ Línea, zigzag, reticulado. } \\
\hline Técnica & Rebaje y falso relieve. & \multicolumn{2}{|c|}{ Incisión (punzón) e impresión (peine). } \\
\hline Combinación de motivos & $\begin{array}{l}\text { La figura representada es la contenida entre } \\
\text { los surcos. Las líneas no forman parte del } \\
\text { dibujo, sino que lo delimitan. El espacio } \\
\text { no decorado juega un papel importante } \\
\text { en el orden de los diseños. }\end{array}$ & \multicolumn{2}{|c|}{$\begin{array}{l}\text { Se parte de línea recta vertical y/u horizontal para orga- } \\
\text { nizar los diseños en el panel. Los espacios no decorados } \\
\text { se integran como elemento decorativo. }\end{array}$} \\
\hline $\begin{array}{l}\text { Temática de los diseños } \\
\text { geométricos }\end{array}$ & Participan siempre figuras circulares. & \multicolumn{2}{|c|}{$\begin{array}{l}\text { Preeminencia de los rectilíneos con gran variedad de } \\
\text { orientaciones. }\end{array}$} \\
\hline $\begin{array}{l}\text { Temática de los diseños } \\
\text { figurativos }\end{array}$ & $\begin{array}{l}\text { Objetos de la cultura y de la naturaleza. Las } \\
\text { figuras humanas son secundarias. }\end{array}$ & $\begin{array}{l}\text { Escasos. Objetos de la } \\
\text { cultura (caras humanas). } \\
\text { Figuras principales. }\end{array}$ & $\begin{array}{l}\text { Escasos. Objetos de la natu- } \\
\text { raleza (soliformes y ciervos) } \\
\text { Figuras principales. }\end{array}$ \\
\hline $\begin{array}{l}\text { Variedad formal de los } \\
\text { motivos }\end{array}$ & Abundancia de formas derivadas. & $\begin{array}{l}\text { Abundancia de formas } \\
\text { derivadas. }\end{array}$ & $\begin{array}{l}\text { Abundancia de formas deriva- } \\
\text { das y además se tiende a reite- } \\
\text { rar un mismo elemento. }\end{array}$ \\
\hline Forma de representar & $\begin{array}{l}\text { Objetos artificiales: naturalista. Elementos } \\
\text { de la naturaleza: estilizados. Figura } \\
\text { humana: esquemática y casi ausente. }\end{array}$ & $\begin{array}{l}\text { No se representan ob- } \\
\text { jetos artificiales. Figura } \\
\text { humana: esquemática. }\end{array}$ & $\begin{array}{l}\text { No se representan objetos } \\
\text { artificiales. Elementos de la } \\
\text { naturaleza: esquemáticos. }\end{array}$ \\
\hline $\begin{array}{l}\text { Participación del soporte } \\
\text { (relación soporte-diseño) }\end{array}$ & $\begin{array}{l}\text { Horizontal o inclinado. El soporte par- } \\
\text { ticipa en la composición. }\end{array}$ & \multicolumn{2}{|c|}{ Decoración se distribuye rítmicamente en el panel. } \\
\hline Articulación & Panel sin segmentación. & Segmentación vertical. & Ausencia de segmentación. \\
\hline Lectura del panel & Vertical. & Circular-horizontal. & Oblicua y continua. \\
\hline Orientación & $\begin{array}{l}\text { Oblicua. Figura principal a partir de la } \\
\text { que se articula todo el diseño. }\end{array}$ & $\begin{array}{l}\text { Vertical. Fácil aislar } \\
\text { motivos. No hay figura } \\
\text { principal. }\end{array}$ & $\begin{array}{l}\text { Horizontal. Difícil aislar } \\
\text { motivos. No hay figura } \\
\text { principal. }\end{array}$ \\
\hline Composición del panel & $\begin{array}{l}\text { Panel integrado. Predominio del conjunto } \\
\text { del panel sobre el motivo. }\end{array}$ & \multicolumn{2}{|c|}{$\begin{array}{l}\text { Soporte y diseño integrados. El soporte potencia la conti- } \\
\text { nuidad del diseño, que predomina sobre el motivo. }\end{array}$} \\
\hline
\end{tabular}

Tabla 2. Características principales del arte rupestre de estilo Atlántico y de la cerámica Penha y Campaniforme. 
en un nivel espacial (Prieto 1999a, 2005) se presentan en la Tabla 2.

\section{Sociedades protoestatales}

En torno al siglo IV antes de Cristo comienza la Segunda Edad del Hierro ${ }^{5}$ en la que los asentamientos se monumentalizan, complejizándose los sistemas defensivos con parapetos, grandes murallas, arquitectura ornamentada y escultura monumental. Si en la anterior etapa se ocupaban las tierras altas, menos fértiles pero más fáciles de trabajar, ahora se ocupan los valles, en busca de tierras más productivas, aumenta el tamaño de los asentamientos y se observa cierta jerarquización en los mismos. Mientras algunos castros o asentamientos fortificados, teniendo en cuenta su tamaño parecen albergar varias unidades familiares, a modo de pequeñas aldeas, otros, de mayor tamaño y generalmente situados en posiciones dominantes en el territorio, presentan ciertas subdivisiones internas, mayor amplitud $y$, a juzgar por su tamaño, debieron cobijar a numerosos núcleos familiares. Es en la Segunda Edad del Hierro cuando se generaliza el uso de silos y grandes sistemas de almacenamiento de grano. En estos grandes castros no prima la proximidad a las tierras más productivas, sino que se prioriza el criterio defensivo, mientras que las aldeas fortificadas se sitúan en los valles, anteponiendo la cercanía a las tierras más fértiles sobre la defensa (Parcero 2000). Esto último podría ser interpretado como un síntoma de algún tipo de sistema tributario que algunos grupos, que ocupaban los grandes castros, recibirían de aquellos que habitan las zonas más propicias para el desarrollo de la actividad agrícola. Parece producirse un paso más hacia el desarrollo del Estado. Aunque se conservan algunas características propias de la sociedad anterior, como cierta movilidad que parece reflejarse en la discontinuidad en el poblamiento de los castros y mantenimiento de la ideología heroica, en esta época

\footnotetext{
${ }^{5}$ En Europa la sociedad que mejor cumple las características de un Estado es el Imperio romano, sin embargo, de manera general podemos aplicar el término protoestatal a las sociedades del Hierro II en el noroeste de España, dado que se dan soluciones sociales próximas a lo que podría ser un Estado en el sentido de Clastres (1981).
}

asistimos a un cambio claro en la cultura material y al surgimiento de sociedades protoestatales. Dicho cambio podría estar relacionado con la aparición del estilo Esquemático Atlántico para el arte rupestre y de la cerámica Estampillada.

Estilo Esquemático Atlántico (EEA). Este tipo de arte rupestre ha sido observado, por el momento, en el noroeste de Iberia, concretamente en el norte de Portugal y en Galicia. Aunque su cronología no ha sido totalmente delimitada es segura su posterioridad al estilo Atlántico, por lo que, en todo caso, este estilo estaría inserto en una sociedad estatal o protoestatal. Los diseños que lo componen son fundamentalmente cazoletas, círculos simples, cruces inscritas, herraduras, podomorfos, antropomorfos y soliformes. Este estilo de arte rupestre se define por las características formales mostradas en la Tabla 3 (Santos 2004).

Cerámica Incisa-impresa y Estampillada. Esta cerámica mantiene en uso el mismo tipo de elementos decorativos, sin embargo, se añade un elemento curvilíneo de importancia, el círculo, con gran riqueza en sus variantes. Se detectan dos rupturas estilísticas hasta llegar al momento en que se desarrolla la cerámica Estampillada (que es contemporánea al EEA). Después de la Campaniforme, encontramos un aumento de la simplicidad decorativa y una reducción de recipientes decorados en la denominada cerámica Incisa-impresa, que actúa de transición estilística, ya que posee rasgos de continuidad con el momento anterior, pero introduce otros nuevos que serán desarrollados plenamente en la Segunda Edad del Hierro, siendo uno de los más destacables la introducción de segmentación horizontal del espacio decorativo que requiere una mirada o lectura plenamente vertical.

Con la introducción de la cerámica Estampillada, se vuelve a producir una fuerte variabilidad y un desarrollo más complejo de la horizontalidad de los diseños, en los que la lectura obligada del panel es mixta, ya que se requiere una mirada primero vertical y luego horizontal para poder abarcar la integridad del diseño, que sufre una fuerte segmentación tanto vertical como horizontal. Es la primera vez que se pueden aislar motivos y 
que, en algunos casos, quizás haya una jerarquización de ellos en sentido vertical, ya que algunos destacan más que otros y poseen un orden casi estandarizado. Las características que definen la decoración de esta cerámica en un nivel espacial (Prieto 1999a, 2007) son presentadas en la Tabla 3 .

\section{Estudio comparativo de la cultura material}

Como ya dijimos, inspirándonos en el método estructuralista-antropológico levistraussiano (Lévi-Strauss 1987), buscamos relaciones de compatibilidad entre todos los niveles que constituyen la realidad. De este modo, y a través de la comparación de la decoración del arte rupestre y de la cerámica, hemos detectado un patrón de regularidad formal para las sociedades preestatales y otro para las estatales, como veremos seguidamente (Figura 2).

Comparación de estilos rupestres. Con la introducción del EEA se producen cambios sustanciales: aumenta el número de tipos de diseños, aunque las variantes o figuras derivadas de los mismos disminuye, es decir, existe cierta rigidez formal en cada uno de los motivos. En el EEA existen, asimismo, más técnicas de grabado. En lo que a los motivos figurativos se refiere, son raras las representaciones claras de elementos de la naturaleza. Este aparente distanciamiento de la naturaleza

\begin{tabular}{|c|c|c|c|}
\hline $\begin{array}{l}\text { Aspectos formales a } \\
\text { considerar en el panel }\end{array}$ & Estilo Esquemático Atlántico & $\begin{array}{l}\text { Cerámica } \\
\text { Incisa-impresa }\end{array}$ & Cerámica Estampillada \\
\hline Elementos decorativos & $\begin{array}{l}\text { Punto, línea y círculo. No siempre se dis- } \\
\text { ponen en torno a un punto central. }\end{array}$ & \multicolumn{2}{|c|}{ Línea, zigzag, reticulado, triángulo, círculo. } \\
\hline Técnica & Grabado simple, rebaje, vaciado. & \multicolumn{2}{|c|}{ Cordones, incisión e impresión (estampilla). } \\
\hline Combinación de motivos & $\begin{array}{l}\text { Los surcos forman parte de los diseños. } \\
\text { Identificación entre surco y figura. }\end{array}$ & \multicolumn{2}{|c|}{$\begin{array}{l}\text { Se parte de inflexiones en el recipiente y secundariamente } \\
\text { de la línea recta horizontal para organizar los diseños } \\
\text { en el panel. }\end{array}$} \\
\hline $\begin{array}{l}\text { Temática de los diseños } \\
\text { geométricos }\end{array}$ & Formados por círculos y/o líneas. & $\begin{array}{l}\text { Predominio de los recti- } \\
\text { líneos, escasa presencia } \\
\text { de curvilíneos (círculos } \\
\text { simples). }\end{array}$ & $\begin{array}{l}\text { Predominio de los rectilíneos, } \\
\text { pero cobran importancia los } \\
\text { curvilíneos (especialmente } \\
\text { combinaciones de círculos). }\end{array}$ \\
\hline $\begin{array}{l}\text { Temática de los diseños } \\
\text { figurativos }\end{array}$ & $\begin{array}{l}\text { No se representan elementos de la natu- } \\
\text { raleza y sí de la cultura. La figura humana } \\
\text { cobra protagonismo. }\end{array}$ & \multicolumn{2}{|c|}{$\begin{array}{l}\text { Casi no se representan, cuando están presentes son } \\
\text { elementos de la naturaleza. }\end{array}$} \\
\hline $\begin{array}{l}\text { Variedad formal de los } \\
\text { motivos }\end{array}$ & Reducida. Reiteración del mismo diseño. & $\begin{array}{l}\text { Reducida. Se tiende } \\
\text { a reiterar el mismo } \\
\text { elemento. }\end{array}$ & $\begin{array}{l}\text { Combinación de la reitera- } \\
\text { ción del mismo elemento con } \\
\text { presencia relativa de formas } \\
\text { derivadas. }\end{array}$ \\
\hline Forma de representar & $\begin{array}{l}\text { Elementos de la naturaleza: esquemáti- } \\
\text { cos y casi inexistentes. Figura humana: } \\
\text { estilizada. }\end{array}$ & \multicolumn{2}{|l|}{ Geométrica. } \\
\hline $\begin{array}{l}\text { Participación del soporte } \\
\text { (relación soporte- } \\
\text { diseño) }\end{array}$ & $\begin{array}{l}\text { Horizontal, inclinado y vertical. Separación } \\
\text { formal entre grabado y soporte. }\end{array}$ & \multicolumn{2}{|c|}{$\begin{array}{l}\text { Decoración presenta una distribución disociada en el } \\
\text { panel. }\end{array}$} \\
\hline Articulación & Ausencia de segmentación en el panel. & $\begin{array}{l}\text { Segmentación del } \\
\text { diseño global en } \\
\text { horizontal. }\end{array}$ & $\begin{array}{l}\text { Segmentación del diseño global } \\
\text { en horizontal y vertical. A } \\
\text { veces se superponen diferentes } \\
\text { motivos }\end{array}$ \\
\hline Lectura del panel & Mixta: horizontal y vertical. & Lectura vertical. & Lectura vertical. \\
\hline Orientación & $\begin{array}{l}\text { Anárquica o reticulada. No existe figura } \\
\text { principal. }\end{array}$ & $\begin{array}{l}\text { Horizontal. } \\
\text { Ordenada. }\end{array}$ & $\begin{array}{l}\text { Mixta: horizontal y vertical. } \\
\text { Ordenada. }\end{array}$ \\
\hline Composición del panel & $\begin{array}{l}\text { Desintegración del panel. Predominio del } \\
\text { motivo particular sobre el panel. }\end{array}$ & \multicolumn{2}{|c|}{$\begin{array}{l}\text { Desintegración entre soporte y diseño. El soporte marca } \\
\text { rupturas en el diseño. Los motivos se individualizan. }\end{array}$} \\
\hline
\end{tabular}

Tabla 3. Características principales del arte rupestre de estilo Esquemático Atlántico y de la cerámica Incisa-impresa y Estampillada. 
se observa en la separación estética entre el panel (elemento artificial) y el soporte (elemento natural), ya que éste no interviene en las composiciones, se pierde ese valor topográfico que parecían tener las rocas en el EA. En cuanto a la composición de los paneles, en el EEA existe cierta desintegración o desconexión entre los diseños y surge, por así decirlo, una individualización de los motivos, que cobran protagonismo en detrimento del conjunto de la composición. Dicha desintegración genera un espacio uniforme que en algunos paneles, como los formados exclusivamente por cazoletas o por la reiteración de cruces inscritas con el mismo tamaño y forma, podríamos calificar de estático, frente a un espacio dinámico en el EA, que se consigue con la presencia de líneas sinuosas que conducen la mirada desde la figura principal hacia las secundarias o con la disposición oblicua de los diseños en los paneles figurativos.

Comparación de estilos cerámicos. Los dos cambios más fuertes que se producen en los espacios decorados de la cerámica se observan, en primer lugar, en la Campaniformey, en segundo lugar, en la Estampillada. En el primer caso se introduce por primera vez la horizontalidad continua como un elemento principal que rige los diseños (frente a la verticalidad de la cerámica Penha), que se integran perfectamente en el cuerpo del recipiente resaltando sus sinuosidades. En cambio, su distribución en bandas provoca una lectura oblicuavertical dinámica en la que la mirada sólo necesita hacer un recorrido en dicho sentido para abarcar la totalidad del panel. No destaca ningún motivo sobre otro, dado que no se pueden aislar, y presentan siempre los mismos tamaños, son limitados en cuanto a variedad y tienden a reiterarse $o$ a derivarse (bien en matices de los diseños, o bien, gracias a la combinación de técnicas o instrumentos). Lo importante es el soporte decorado en su totalidad, que es entendido como elemento principal dentro del conjunto cerámico conocido para el período, los motivos figurativos son esquemáticos y tan escasos como excepcionales.

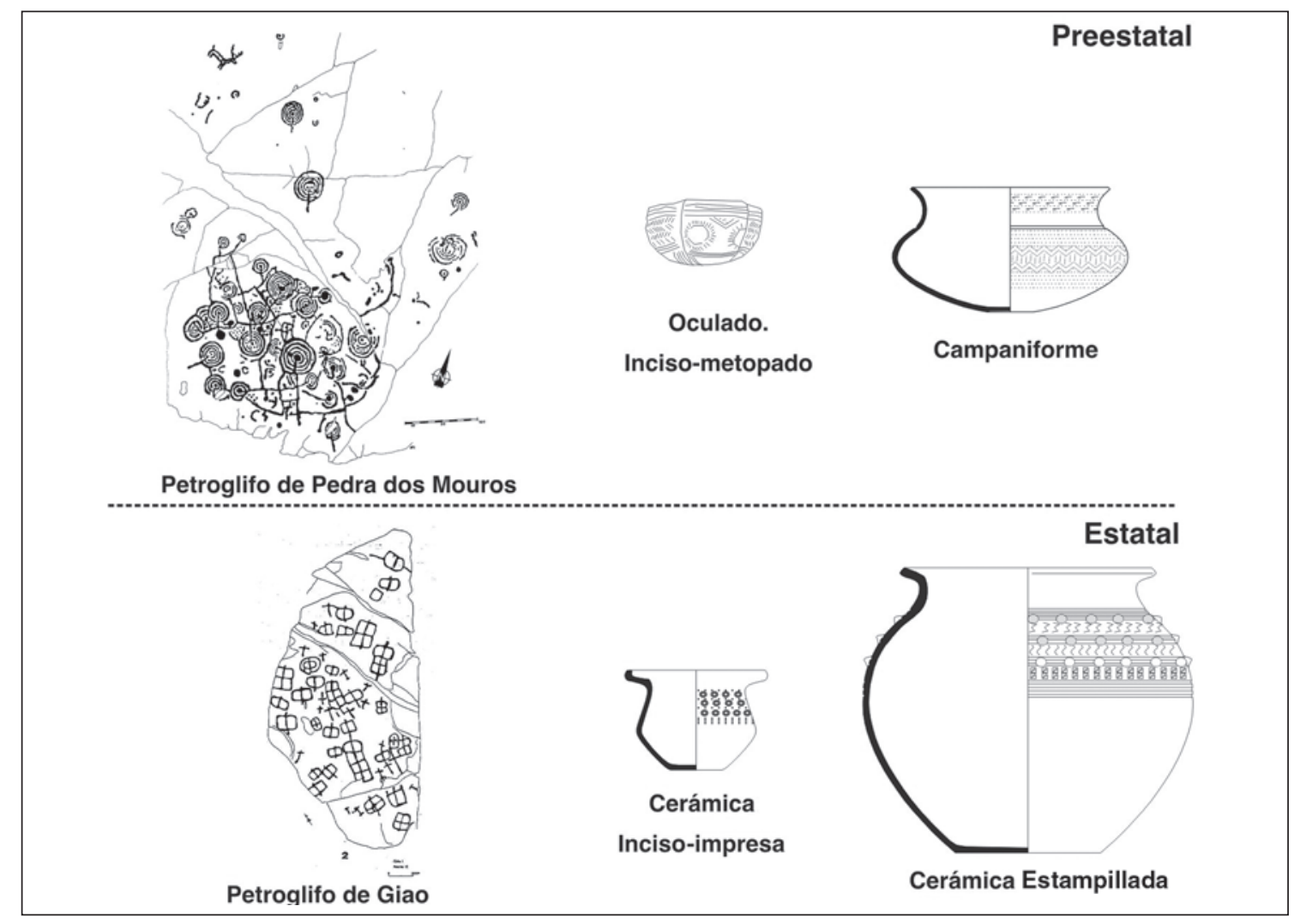

Figura 2. Comparación entre arte rupestre y cerámica: Europa preestatal y estatal. 
En la cerámica Estampillada, en cambio, luego de un momento de transición temporal y formal, en el que se manufactura la cerámica Incisa-impresa, se llega al mayor grado de desarrollo de la horizontalidad, en la que los motivos se organizan de manera segmentada no sólo horizontalmente sino también en vertical, empezando a destacar algunos de ellos dentro del conjunto, aumenta la variedad de los diseños y no encontramos tantas variantes de los mismos. El sentido de la mirada debe ser en primer lugar vertical, siendo necesario hacer pausas a causa de la desintegración existente entre el panel y los motivos debido a las rupturas que marca el soporte sobre el diseño $y$, en segundo lugar, la mirada debe ser horizontal, para poder observar en su totalidad, de manera circular, el orden de los motivos en el recipiente. La cerámica Estampillada es un tipo de recipiente especial dentro del conjunto de los decorados del período. ${ }^{6}$

Aunque en las sociedades preestatales hay un mayor número de semejanzas entre la decoración del arte rupestre y de la cerámica, destaca un buen número de diferencias. Las primeras se observan en un nivel global del soporte, mientras que las segundas se encuentran en el nivel de detalle:

- Compatibilidad directa (semejanzas). Elementos delimitadotes y combinación de motivos, variedad formal de los motivos, relación soporte-diseño, lectura del panel y composición del panel.

- Compatibilidad inversa (diferencias). Elementos decorativos, temática de los diseños, tanto geométricos como figurativos, forma de representar y orientación del esquema.

En las sociedades protoestatales aumentan los niveles de semejanza entre arte rupestre y cerámica, ya no sólo

\footnotetext{
${ }^{6}$ En la cerámica hemos tratado cuatro fases para hacer más comprensibles los cambios estilísticos y para mostrar que los cambios sociales no se ven reflejados bruscamente a través de ella. Nos hemos centrado en las dos fases que son coetáneas con los petroglifos, ya que es en esos dos momentos cuando se observan los cambios más fuertes en relación con la organización espacial de los diseños.
}

en el nivel de organización global del espacio, sino también en algunos aspectos más de detalle.

- Compatibilidad directa (semejanzas). Elementos decorativos, elementos delimitadores, temática de los diseños geométricos, variedad formal de los motivos, relación soporte-diseño, lectura del panel y composición del panel.

- Compatibilidad inversa (diferencias). Temática de los diseños figurativos, combinación de los motivos, forma de representar y orientación del esquema.

Las diferencias son las que expresan la esfera social a la que se corresponde cada uno de estos tipos de soporte, mientras que las semejanzas actúan como motor social unitario, representando aspectos más generales de la sociedad que los ha creado (Figura 2).

\section{- El valle del Aconcagua (Chile) COMO EJEMPLO}

En este estudio consideramos las propuestas cronológicas desarrolladas por Rodríguez y colaboradores (2004) y Troncoso (2005). Este último autor ha comparado en el valle del Aconcagua el arte rupestre con otros sistemas de representación como la cerámica, planteando la existencia de una dicotomía en la que el arte rupestre y la cerámica reproducen una diferenciación entre dos espacios disímiles (Troncoso 2006). Esto fue denominado por Sánchez (2000) "área de interdigitación". Por un lado, la cuenca de Putaendo ofrece abundante arte rupestre al igual que el Norte Chico, y dos tipos cerámicos, uno de ellos es una alfarería similar a la de la cultura diaguita del Norte Chico, y el otro, local, se denomina Putaendo Rojo sobre Blanco. Por otro lado, la cuenca de San Felipe-Los Andes con Maipú-Mapocho, por el contrario, presenta un número más escaso de sitios de arte rupestre y la cerámica es de los tipos Putaendo Rojo Engobado y Aconcagua Salmón (Troncoso 2004, 2006).

En el período Intermedio Tardío, tanto la cultura diaguita del norte en el valle de Illapel como la cultura 
Aconcagua podrían ser paralelizables, a grandes rasgos, con las culturas del Neolítico o de los Inicios de la Edad del Bronce en Europa. Son sociedades cuya principal manifestación material se desarrolla a través de la cerámica y el arte rupestre, escaso desarrollo de la arquitectura, como es propio de sociedades nómadas o semiitinerantes, escasa desigualdad social y estructuración del paisaje en clave de desplazamiento.

Los petroglifos asignables al período Intermedio Tardío o Estilo I (Troncoso 2004) presentan estrechos paralelismos con el estilo Atlántico (EA). Observamos un predominio de los motivos circulares que aparecen interconectados bien a través de líneas, por tangencialidad o por superposición. Hay un claro dominio del conjunto sobre cada uno de los diseños, un alto nivel de integración impide separar con facilidad cada uno de los elementos de la composición (Tabla 4).

Mientras entre 1000-1475 DC se desarrolla en el valle de Illapel el estilo cerámico diaguita, en el valle del Aconcagua, entre 900-1430 DC, de manera contemporánea, se desarrolla la cultura Aconcagua. Las culturas antecesoras de la diaguita, El Molle y Las Animas, difieren en cuanto a los motivos decorativos empleados, pero avanzan en cierto modo la organización espacial de la decoración diaguita. Por el contrario, los pueblos Bato y Llolleo, predecesores de la cultura Aconcagua, presentan pocos elementos de continuidad con ésta, si bien una buena parte de los rasgos decorativos de la

\begin{tabular}{|c|c|c|c|}
\hline $\begin{array}{l}\text { Aspectos formales a } \\
\text { considerar en el panel }\end{array}$ & $\begin{array}{l}\text { Arte rupestre del período } \\
\text { Intermedio Tardío }\end{array}$ & $\begin{array}{l}\text { Cerámica } \\
\text { Diaguita }\end{array}$ & Cerámica Aconcagua \\
\hline Elementos decorativos & $\begin{array}{l}\text { Círculos simples y concéntricos, puntos y } \\
\text { líneas. Escasos motivos figurativos. }\end{array}$ & \multicolumn{2}{|c|}{$\begin{array}{l}\text { Zigzags, reticulados, ondas, cadenas, ajedrezados, } \\
\text { rombos, laberintos. }\end{array}$} \\
\hline Técnica & $\begin{array}{l}\text { Piqueteado, las figuras se hacen visibles por } \\
\text { contraste cromático con el fondo. }\end{array}$ & \multicolumn{2}{|c|}{ Pintura (blanca, roja, negra, salmón). } \\
\hline Combinación de motivos & $\begin{array}{l}\text { Círculos irregulares conectados por tan- } \\
\text { gencialidad, superposición o unidos por } \\
\text { líneas. }\end{array}$ & \multicolumn{2}{|c|}{$\begin{array}{l}\text { Se parte de línea recta vertical y/u horizontal para } \\
\text { organizar los diseños en el panel. Los espacios no } \\
\text { decorados se integran como elemento decorativo. }\end{array}$} \\
\hline $\begin{array}{l}\text { Temática de los diseños } \\
\text { geométricos }\end{array}$ & $\begin{array}{l}\text { Acumulación de círculos simples y líneas. } \\
\text { Las escasas representaciones figurativas se } \\
\text { generan combinando círculos y líneas. }\end{array}$ & \multicolumn{2}{|c|}{$\begin{array}{l}\text { Preeminencia de los rectilíneos con gran variedad de } \\
\text { orientaciones. }\end{array}$} \\
\hline \multirow[t]{2}{*}{$\begin{array}{l}\text { Temática de los diseños } \\
\text { figurativos }\end{array}$} & \multirow[t]{2}{*}{ Figuras humanas y animales. } & \multicolumn{2}{|c|}{$\begin{array}{l}\text { Escasos. Objetos de la cultura como motivo } \\
\text { principal. }\end{array}$} \\
\hline & & $\begin{array}{l}\text { Caras de } \\
\text { animales. }\end{array}$ & $\begin{array}{l}\text { Antropomorfos y zoomorfos } \\
\text { (cámelidos). }\end{array}$ \\
\hline $\begin{array}{l}\text { Variedad formal de los } \\
\text { motivos }\end{array}$ & $\begin{array}{l}\text { Escasa, las variaciones se hacen combinando } \\
\text { círculos y líneas, a través de división interna } \\
\text { o por añadido de apéndices. }\end{array}$ & \multicolumn{2}{|c|}{$\begin{array}{l}\text { Abundancia de formas derivadas y tendencia a reiterar } \\
\text { un mismo elemento. }\end{array}$} \\
\hline Forma de representar & $\begin{array}{l}\text { No es posible identificar elementos artifi- } \\
\text { ciales. Fuerte esquematismo. }\end{array}$ & \multicolumn{2}{|c|}{$\begin{array}{l}\text { No se representan objetos artificiales. Figura humana/ } \\
\text { animal: esquemática. }\end{array}$} \\
\hline $\begin{array}{l}\text { Participación del soporte } \\
\text { (relación soporte-diseño) }\end{array}$ & $\begin{array}{l}\text { Aparentemente el soporte no participa en } \\
\text { la composición. }\end{array}$ & \multicolumn{2}{|c|}{$\begin{array}{l}\text { Decoración presenta una distribución rítmica en el } \\
\text { panel. }\end{array}$} \\
\hline Articulación & $\begin{array}{l}\text { Figura principal en torno a la cual se yuxta- } \\
\text { ponen otras sin un orden concreto. }\end{array}$ & \multicolumn{2}{|c|}{ Segmentación vertical y/u horizontal. } \\
\hline Lectura del panel & Indistinto. & \multicolumn{2}{|c|}{ Circular-horizontal y/u oblicua y continua. } \\
\hline Orientación & Indistinta. & \multicolumn{2}{|c|}{$\begin{array}{l}\text { Vertical y/u horizontal. Fácil aislar elementos y difícil } \\
\text { aislar motivos. No hay figura principal. }\end{array}$} \\
\hline Composición del panel & $\begin{array}{l}\text { Fuerte integración entre motivos. Un surco } \\
\text { puede ser compartido por varias figuras. }\end{array}$ & \multicolumn{2}{|c|}{$\begin{array}{l}\text { Integración de soporte y diseño. El soporte potencia } \\
\text { la continuidad del diseño, que predomina sobre el } \\
\text { motivo. }\end{array}$} \\
\hline
\end{tabular}

Tabla 4. Características principales del arte rupestre del período Intermedio Tardío en Chile Central y sur del Norte Chico, y de la cerámica Aconcagua y Diaguita. 
cerámica de las fases iniciales de las culturas diaguita y Aconcagua son semejantes, ya que la decoración presenta una mayor sencillez en la organización de los motivos, que se integran plenamente en el soporte-recipiente decorado, predominando los elementos rectilíneos sobre los curvos, con cierta variedad de orientaciones que ocupan espacios proporcionados unos respecto a otros y que están distribuidos de manera rítmica en el panel. No se representan objetos artificiales, y los naturales (caras de animales o jarros pato) son representados esquemáticamente. La lectura de la decoración presenta dos variantes, una circular (en la cerámica metopada, que puede ser tripartita o cuatripartita) y una vertical (en la cerámica que posee una única banda ancha en la que se reiteran los mismos motivos decorativos). El diseño tiene sentido tomado en conjunto dada la dificultad de separar motivos o grupos de motivos con claridad, por ello es difícil aislar un motivo principal, salvo excepciones como, por ejemplo, los camélidos en la cerámica Aconcagua Salmón.

Nuestra observación no es original, ya que a finales del siglo pasado Thomas y Massone (1994) encontraron en "términos estructurales" determinados elementos de la decoración cerámica de diferentes complejos arqueológicos localizados en territorio chileno repetidos, expresados a través de múltiples elementos de cultura material y de las formas de apropiación del espacio y el territorio, que responden a un modelo cosmológico andino. Entre ellos destacaban la cerámica de las culturas Aconcagua, de Arica y diaguita, incluyendo Animas.

Con la integración de la zona al Imperio inca, una sociedad estatal, las comunidades indígenas del valle del Aconcagua sufren una importante transformación que se traduce también en la cultura material, con la adopción de elementos tanto incaicos como diaguitas. De hecho, estos últimos fueron agentes importantes de la expansión incaica hacia Chile Central (Sánchez 2004).

Se observa, al igual que en el caso de Europa Occidental, una desintegración del panel en el arte rupestre; los motivos se individualizan. Existen, asimismo, composiciones consistentes en la reiteración del mismo motivo con ligeras o prácticamente ninguna variante. En definitiva, el motivo individual predomina sobre el conjunto, exactamente al contrario que en la fase anterior donde cada uno de los diseños se mimetiza formando parte de un todo integrado (Tabla 5).

En el último medio siglo de convivencia entre diaguitas e incas en el Norte Chico, no sólo se introduce la cerámica propiamente incaica, sino que se observan cambios en los patrones decorativos diaguitas, estructuralmente muy influidos por la cultura inca. Por el contrario, parece que en el valle del Aconcagua, a partir del carácter monocomponente de los contextos cerámicos, existe una segregación intencional entre la cultura inca y la local de Aconcagua, así los contextos cerámicos incaicos son el resultado de la implantación directa de un contexto cerámico del Norte Chico: “Tendríamos una fórmula de dominio incaico que aprovecha las relaciones previas de la cultura diaguita con el área de Aconcagua y el sustrato cultural andino común entre incas y diaguitas que les permite esa cierta “integración'” (Sánchez 2004:333).

El soporte cerámico de vasijas con influencia diaguita de la cultura Aconcagua, vasijas diaguitas-incas o incas, al igual que los diseños, adquieren una mayor complejidad, son más reducidas las formas derivadas del mismo motivo y abunda su reiteración, los motivos curvilíneos son muy frecuentes al igual que los rectángulos. Se observa una clara división de los motivos y grupos de motivos que están disociados del panel, ya que se marcan rupturas fuertes en el diseño, en el que se pueden aislar los motivos que parecen principales. Se observa una representación de elementos de la cultura, en este caso asociados a ropa o al adorno corporal, y los rostros de los recipientes antropomorfos son representados de manera naturalista. Es necesaria una lectura mixta, horizontal y vertical para poder abarcar la decoración integral de los recipientes, en algunos de ellos, se pueden incluso reconocer las seis dimensiones de las que habla Aristóteles (delante-detrás, derechaizquierda, arriba-abajo), muy excepcional en momentos anteriores. Aunque la distribución de la cerámica y la diversidad de los patrones decorativos muestran que 


\begin{tabular}{|c|c|c|}
\hline $\begin{array}{l}\text { Aspectos formales a } \\
\text { considerar en el panel }\end{array}$ & Arte rupestre del período Inca & $\begin{array}{l}\text { Cerámica Aconcagua de influencia diaguita/ } \\
\text { cerámica Diaguita-inca / cerámica Inca }\end{array}$ \\
\hline Elementos decorativos & $\begin{array}{l}\text { Diseños cuadrangulares, ondas, círculos, } \\
\text { líneas angulosas. }\end{array}$ & $\begin{array}{l}\text { Zigzags, reticulados, ondas, cadenas, ajedrezados, } \\
\text { rombos, triángulos, cuadrados. }\end{array}$ \\
\hline Técnica & $\begin{array}{l}\text { Piqueteado, las figuras se hacen visibles por } \\
\text { contraste cromático con el fondo. }\end{array}$ & Pintura (blanca, roja, negra, marrón). \\
\hline Combinación de motivos & Yuxtaposición. Escasa tangencialidad. & $\begin{array}{l}\text { Se parte de inflexiones en el recipiente y secunda- } \\
\text { riamente de la línea recta horizontal para organizar } \\
\text { los diseños en el panel. }\end{array}$ \\
\hline $\begin{array}{l}\text { Temática de los diseños } \\
\text { geométricos }\end{array}$ & Circulares y rectilíneos. & $\begin{array}{l}\text { Predominio de los rectilíneos, escasa presencia de } \\
\text { curvilíneos (ondas). }\end{array}$ \\
\hline $\begin{array}{l}\text { Temática de los diseños } \\
\text { figurativos }\end{array}$ & $\begin{array}{l}\text { Antropomorfos y posibles combinaciones } \\
\text { antropozoomorfas. }\end{array}$ & $\begin{array}{l}\text { Poco representados porque la propia vasija adopta } \\
\text { una forma figurativa, los motivos contribuyen a } \\
\text { "vestir" y realzar dicha forma. }\end{array}$ \\
\hline $\begin{array}{l}\text { Variedad formal de los } \\
\text { motivos }\end{array}$ & $\begin{array}{l}\text { Alta. Combinación de rectilíneos y circulares, } \\
\text { figuras cerradas (cuadrados y círculos) y } \\
\text { abiertas (líneas). }\end{array}$ & $\begin{array}{l}\text { Combinación de la reiteración del mismo elemento } \\
\text { con presencia relativa de formas derivadas. Predominio } \\
\text { de motivos cerrados. }\end{array}$ \\
\hline Forma de representar & Geométrica, figuras simétricas. & $\begin{array}{l}\text { Geométrica, también en las vasijas antropomorfas } \\
\text { o zoomorfas. }\end{array}$ \\
\hline $\begin{array}{l}\text { Participación del soporte } \\
\text { (relación soporte-diseño) }\end{array}$ & $\begin{array}{l}\text { Pueden ser usadas varias caras de un mismo } \\
\text { soporte. }\end{array}$ & $\begin{array}{l}\text { Decoración presenta una distribución disociada en } \\
\text { el panel: varios paneles individualizados en la misma } \\
\text { vasija y relacionados. }\end{array}$ \\
\hline Articulación & $\begin{array}{l}\text { Composiciones y figuras simétricas. } \\
\text { Articulación horizontal. }\end{array}$ & $\begin{array}{l}\text { Segmentación del diseño global en horizontal y } \\
\text { vertical. }\end{array}$ \\
\hline Lectura del panel & Lectura horizontal y vertical. & Lectura mixta: horizontal y vertical. \\
\hline Orientación & Vertical. & Mixta: horizontal y vertical. Ordenada. \\
\hline Composición del panel & $\begin{array}{l}\text { Motivos individualizados, paneles con } \\
\text { un solo motivo, separación entre figuras. } \\
\text { Predominio del diseño concreto sobre la } \\
\text { composición general. }\end{array}$ & $\begin{array}{l}\text { Desintegración entre soporte y diseño. El sopor- } \\
\text { te marca rupturas en el diseño. Los motivos se } \\
\text { individualizan. }\end{array}$ \\
\hline
\end{tabular}

Tabla 5. Características principales del arte rupestre del período Inca en Chile Central y sur del Norte Chico, y de la cerámica Aconcagua Salmón de influencia diaguita, Diaguita-inca e Inca.

las estrategias de expansión y establecimiento del Imperio inca no fueron ni homogéneas ni uniformes a lo largo del territorio ocupado (Bray 2004), a partir de la conquista del Inka se observan cambios profundos en la forma de organizar el espacio decorativo de la cerámica diaguita y de aquella influida por la nueva sociedad estatal (González 2004). Al igual que el caso gallego, en la zona de estudio chilena se observa un cambio en la concepción de los espacios decorativos de la cerámica en el mismo sentido, con un proceso progresivo de la lectura estática en la cerámica diaguita y la Aconcagua (o vertical, u oblicua u horizontal) a la dinámica en la Diaguita-inca e Inca (mixta: horizontal y vertical) (Tabla 5, Figura 3).

\section{* Conclusión}

De manera muy general, hemos observado cómo se han producido cambios en la organización del espacio de dos elementos de cultura material muy diferentes y en dos tipos de formaciones socioculturales que nada tienen que ver históricamente, y cómo dentro de cada uno de los patrones de racionalidad tratados existe una coherencia estructural de los códigos decorativos en ambos espacios fenomenológicos, que se expresa a través de una relación de oposición, que hemos denominado compatibilidad directa e inversa. Esto se hace evidente en aquellos aspectos vinculados a la organización general de los paneles (composición, orientación, lectura, relación con el uso de la superficie 


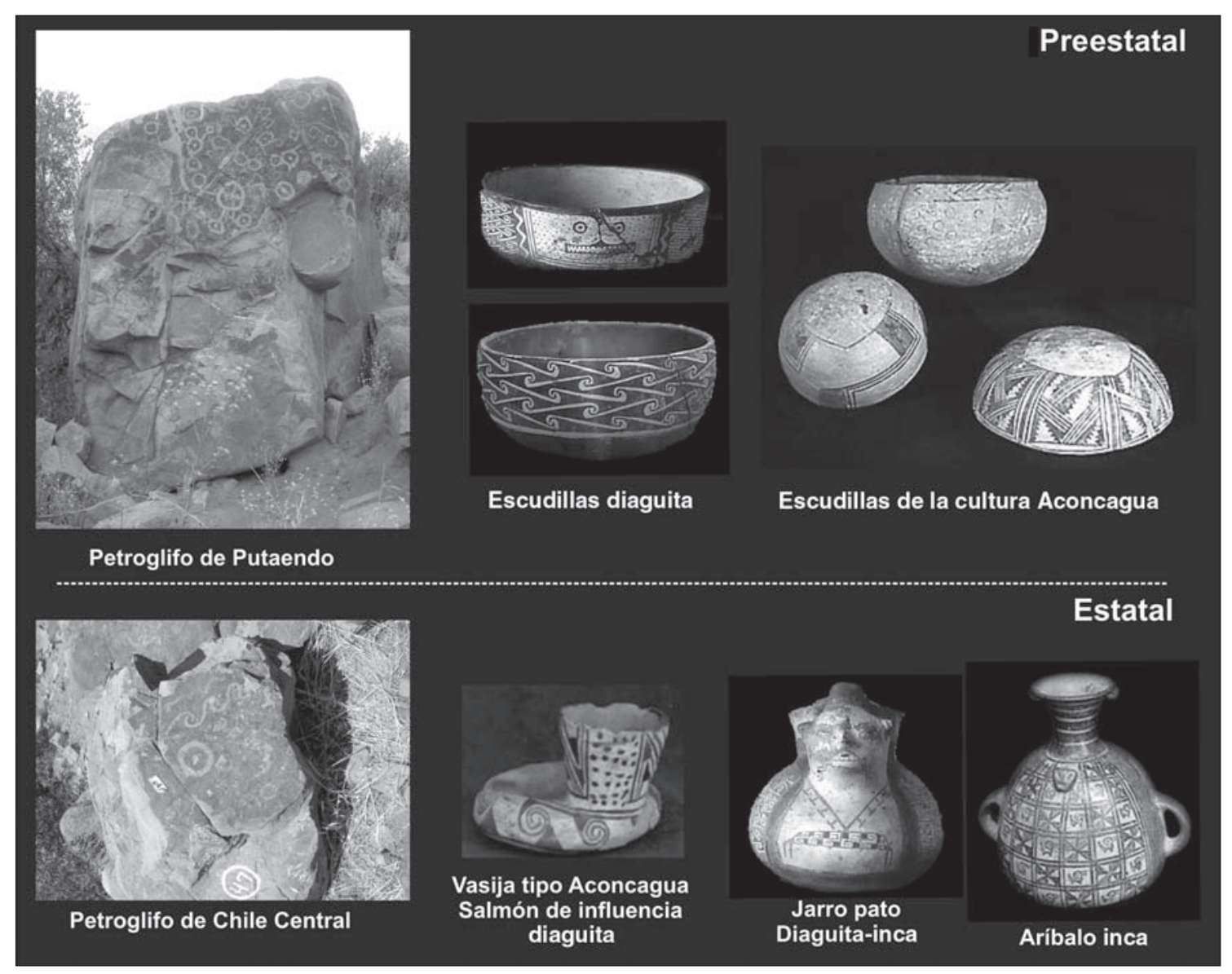

Figura 3. Comparación entre arte rupestre y cerámica: Sudamérica preestatal y estatal. Las fotografías de cerámica han sido tomadas de González y colaboradores (2000).

del panel) más que en los detalles puntuales de la decoración (elementos y motivos). Mientras que los primeros señalan la continuidad social interna, los segundos parecen indicar una separación interna de las diferentes esferas sociales en las que arte rupestre y cerámica se manifiestan: los petroglifos en la esfera sagrada y la cerámica en la esfera cotidiana (tanto doméstica como ritual).

Petroglifos y cerámica presentan ritmos diferentes en un nivel diacrónico, dado que representan y transmiten discursos con una densidad simbólica opuesta y complementaria. Por un lado, el arte rupestre representa lo sagrado-religioso vinculado al poder y orientado al mantenimiento de la tradición, con una voluntad de ser permanente y con un carácter principalmente sustantivo. Está vinculado a un menor número de yacimientos, sus contextos son específicos y rituales y están estratégicamente ubicados en el globo terrestre. Surgen y reflejan una transformación en el concepto de espacio en los momentos de cambio más fuertes en el patrón de racionalidad de las sociedades. Los estilos de arte rupestre realizados por los mismos tipos de sociedad, por muy alejados que estén geográficamente, comparten un patrón formal y un desarrollo de una espacialidad interna más evidente. El arte rupestre presenta menos variabilidad en fases más largas de duración y, por lo tanto, aparenta ser muy conservador. Por el contrario, la cerámica representa lo cotidiano doméstico y/o ritual, su uso es perecedero pero habitual y su carácter es básicamente adjetivo. Está vinculada a un número mayor de yacimientos y contextos, y se asocia a más esferas sociales. Expresa una concepción espacial más limitada aparentemente 
en cuanto a iconografía (motivos geométricos) pero es más difícil de comprender desde nuestra visión en el presente. Expresa un mayor número de cambios en un nivel de organización de los espacios, aunque de naturaleza más simple, parecen más evidentes y su duración es más corta. Se observan gran cantidad de variantes regionales sin romper el patrón formal. La cerámica presenta mayor variabilidad en fases más cortas de duración y parece menos conservadora.

Hemos visto cómo en dos zonas lo suficientemente distantes, tanto geográfica como cronológicamente, se materializaba una serie de transformaciones culturales y sociales paralelas, transitándose de una sociedad con una escasa jerarquización a una sociedad protoestatal en un caso, y plenamente estatal en el otro. Aunque hay matices, podemos afirmar que los patrones de los diseños expresan un cambio semejante en un nivel estructural en los dos ejemplos utilizados. Dichas transformaciones sociales tienen su repercusión y traducción en la producción material y en concreto en la decoración de los petroglifos y la cerámica (Tabla 6).

Interpretamos estas transformaciones materiales como un reflejo de cambios sociales claros, cambios en la organización de comunidades, que en una primera fase (preestatal) se materializa a la comunidad como la célula o la unidad que integra a los individuos y que, en cambio, en una segunda fase (estatal) se materializa una estructuración social en la que se prima a las unidades familiares sobre la comunidad. Esto es, al menos, lo que pudo haber ocurrido en ambas zonas, en las que se abandona definitivamente la forma de organización social primitiva (de carácter integrador, menos dividida, heterogénea) y surge lo que podríamos llamar sociedades campesinas (desintegradora, jerarquizada, estandarizada), donde la familia, como unidad de producción, constituye la base sobre la que se sustenta un determinado sistema sociopolítico.

Aunque ésta es una propuesta preliminar, creemos que la manera de organizar el espacio en todas las esferas fenomenológicas de una sociedad, desde lo macro a lo micro, nos permite definir mejor el concepto de espacio de dichas sociedades y completar un conocimiento que, de otra manera, es más sesgado.

Agradecimientos A los consultores anónimos, ya que sin duda sus comentarios y sugerencias han contribuido a enriquecer este texto. Los errores son responsabilidad nuestra. Este trabajo forma parte del proyecto PGIDITo7PXIB236075PR concedido en 2007 por la Dirección Xeneral de Investigación, Desenvolvimento e Innovación $(\mathrm{I}+\mathrm{C}+\mathrm{I})$, Xunta de Galicia del Plan Gallego INCITE.

\begin{tabular}{|l|l|l|}
\hline \multicolumn{1}{|c|}{ Aspectos en el panel } & \multicolumn{1}{|c|}{ Sociedades preestatales } & \multicolumn{1}{c|}{ Sociedades protoestatales / estatales } \\
\hline Elementos decorativos & Predominio de elementos abiertos. & $\begin{array}{l}\text { Elementos cerrados. Introducción de ele- } \\
\text { mentos nuevos o concepción diferente de los } \\
\text { anteriores. }\end{array}$ \\
\hline $\begin{array}{l}\text { Diseños (elementos } \\
\text { delimitadores) }\end{array}$ & Espacios no decorados: son decorativos. & Espacios no decorados: no son decorativos. \\
\hline $\begin{array}{l}\text { Temática de los motivos } \\
\text { Diseños figurativos }\end{array}$ & $\begin{array}{l}\text { Alejamiento formal entre elementos de arte } \\
\text { rupestre y cerámica. }\end{array}$ & $\begin{array}{l}\text { Aproximación entre elementos de arte rupestre } \\
\text { y cerámica. }\end{array}$ \\
\hline $\begin{array}{l}\text { Variedad formal de los } \\
\text { motivos }\end{array}$ & Abundancia de formas derivadas. & Figura humana más frecuente. \\
\hline $\begin{array}{l}\text { Participación del soporte } \\
\text { relación soporte-diseño) }\end{array}$ & El soporte participa de la composición. & Reducción de formas derivadas. \\
\hline Lectura del panel & Lectura estática. & Lectura dinámica. \\
\hline Composición del panel & $\begin{array}{l}\text { Composición integrada. Importancia del del de disocia de la composición. } \\
\text { conjunto. }\end{array}$ & $\begin{array}{l}\text { Composición desintegrada. Importancia del } \\
\text { detalle. }\end{array}$ \\
\hline Producto final & Diversidad. & Estandarización. \\
\hline
\end{tabular}

Tabla 6. Síntesis general de los cambios espaciales observados en el patrón de regularidad formal de la decoración entre las sociedades preestatales y protoestatales/estatales. 


\section{* Referencias citadas}

Bradley, R., 1997. Rock art and the prehistory of Atlantic Europe. Signing the land. Routledge, Londres.

BraY, T. L., 2004. La alfarería imperial inca: Una comparación entre la cerámica estatal del área de Cuzco y la cerámica de las provincias. Chungara, Revista de Antropología Chilena 36 (2): 365-374.

Clastres, P., 1981. Investigaciones en antropología política. Gedisa, Barcelona.

Cobas, I. y M. P. Prieto, 1998. Regularidades espaciales en la cultura material: La cerámica de la Edad del Bronce y la Edad del Hierro en Galicia. Gallaecia 17: 151-175.

Cobas, I., F. Criado y M. P. Prieto, 1998. Formas de la cultura material cerámica prehistórica y protohistórica en Galicia. Arqueología Espacial 19-20: 597-607.

Criado, F., 1993. Visibilidad e interpretación del registro arqueológico. Trabajos de Prehistoria 50:39-56.

González, C., F. Sánchez, P. Contreras, A. Hernández, V. Goravica, R. Ramírez y M. Hinostroza, 2000. Alfarería indígena chilena. http://www.puc.cl/sw_educ/alfareria/index.html (consulta en junio 18 de 2006).

GonZÁlez, P., 2004a. Arte visual, espacio y poder: Manejo incaico de la iconografía cerámica en distintos asentamientos de la fase Diaguita Inca en el valle de Illapel. Chungara, Revista de Antropología Chilena 36 (2):375-392.

Kristiansen, K., 2001. Europa antes de la Historia. Los fundamentos prehistóricos de la Europa de la Edad del Bronce y la primera Edad del Hierro. Ediciones Península, Barcelona.

Kristiansen, K. y T. B. LARSSOn, 2006. La emergencia de la sociedad del Bronce. Viajes, transmisiones y transformaciones. Editorial Bellaterra, Barcelona.

LÉvi-Strauss, C., 1986. La alfarera celosa. Paidós Studio/Básica, Barcelona.

1987. Antropología estructural. Paidós Studio/Básica, Barcelona.

Parcero, C., 2000. Tres para dos. Las formas de poblamiento en la Edad del Hierro del NO. Trabajos de Prehistoria 57 (1): 75-95.

Prieto, M. P., 1999a. Forma, estilo y contexto en la cultura material cerámica de la Edad del Bronce gallega: Cerámica campaniforme y cerámica no decorada. Tesis de Doutoramento 98. Humanidades e Ciencias Sociais. Servicio de Publicacións e Intercambio Científico, edición en CD. Universidad de Santiago de Compostela.

1999b. Caracterización del estilo cerámico de la Edad del Bronce en Galicia: Cerámica campaniforme y cerámica no decorada. Complutum 10: 71-90.

2005. Síntesis de la cerámica neolítica en Galicia. Estudio desde la perspectiva de la arqueología del paisaje. Actas del III Congreso del Neolítico en la Península Ibérica, pp. 337-48. Santander.

2007. Volviendo a un mismo lugar: Recipientes y espacios en un monumento megalítico gallego (NO de España). Revista Portuguesa de Arqueología 10 (2): 101-125.

Prieto, M. P., F. Criado e I. Cobas, 2003. Patterns of spatial regularity in Late Prehistoric material culture styles of the NW Iberian Peninsula. En Prehistoric pottery. People, pattern and purpose, A. Gibson (Ed.), pp. 147-187. BAR International Series 1156, Oxford.

Rodríguez, J., C. Becker, P. González, A. Troncoso y D. Pavlovic, 2004. La cultura diaguita en el valle del río Illapel. Chungara, Revista de Antropología Chilena 36 (2): 739-751.

SÁnchez, R., 2000. Cultura Aconcagua en el valle del río Aconcagua, una discusión sobre su cronología e hipótesis de organización dual. Contribución Arqueológica 5, vol. 1, pp. 147-160.

2004. El Tawantinsuyo en Aconcagua (Chile Central). Chungara, Revista de Antropología Chilena 36 (2):325-336.

SANTOS, M., 2004. Arte rupestre: Estilo y construcción social del espacio en el noroeste de la península ibérica. Tesis doctoral. Facultad de Filosofía y Antropología Social, Universidad de Santiago de Compostela, Santiago de Compostela.

2005. Sobre la cronología del arte rupestre Atlántico en Galicia. Arqueoweb 7(2). sept./dic. 2005. http://www.ucm. es/info/arqueoweb/numero7_z/conjunto7_z.htm

2008a. Petroglifos y paisaje social en la prehistoria reciente del noroeste de la península ibérica. TAPA 38.

$2008 \mathrm{~b}$. Some notes about social space and its influence in the design of labyrinth figure. Man in India 88 (2/3):357-366.

Santos, M. y F. Criado, 1998. Espacios rupestres: Del panel al paisaje. Arqueología Espacial 19-20: 579-596. 
2000. Deconstructing rock art spatial grammar in the Galician Bronze Age. En Signifying place and space. World perspectives of rock art and landscape, G. Nash. (Ed.), pp. 11-22. BAR International Series 902, Oxford.

Thomas, C. y C. Massone, 1994. El complejo cultural Aconcagua; una consideración desde un enfoque estructural. Actas del $2^{\circ}$ Taller de Arqueología de Chile Central. http://www.arqueologia. $\mathrm{cl} /$ actas2/thomasymassone.pdf (consulta en enero 2007).

Troncoso, A., 2004. El arte de la dominación: Arte rupestre y paisaje durante el período Incaico en la cuenca superior del río Aconcagua. Chungara, Revista de Antropología Chilena 36 (2): 453-461.

2005. Hacia una semiótica del arte rupestre de la cuenca superior del río Aconcagua, Chile Central. Chungara, Revista de Antropología Chilena 37 (1): 21-35.

2006. Arte rupestre en la cuenca del río Aconcagua: Formas, sintaxis, estilo, espacio y poder. Tesis doctoral. Facultad de Geografía e Historia, Universidad de Santiago de Compostela, Santiago de Compostela. 